\title{
The fate of ileorectal anastomosis in Crohn's disease
}

\author{
J. H. BURMAN, W. T. COOKE, AND J. ALEXANDER WILliamS \\ From the Nutritional and Intestinal Unit, The General Hospital, Birmingham
}

SUMMARY An assessment has been made of 25 patients who have undergone ileorectal anastomosis for Crohn's disease. The rate of anastomotic leakage was high (32\%) but was fatal in only one patient. The likelihood of leakage was not affected by a safety valve ileostomy, failure to excise all diseased bowel, or steroid therapy. The overall recurrence rate was 60 per cent. This was not affected by the age of the patient, duration of the disease, steroid therapy, or anastomotic leak but was affected adversely by the presence of concurrent small bowel disease and by residual rectal disease at the site of the anastomosis.

It might be thought that the known tendency for Crohn's disease to recur would preclude conservative surgery of the large bowel in this disease. Nonetheless successful results have been claimed for ileorectal anastomosis (Jones, Lennard-Jones, and Lockhart-Mummery, 1966; Hawk, Turnbull, and Schofield, 1970).

This paper reports an enquiry into the long-term progress of patients with Crohn's disease of the colon treated by ileorectal anastomosis at the General Hospital, Birmingham.

\section{Material}

There were 25 patients, all of whom had Crohn's disease of the colon histologically confirmed. There were 12 men and 13 women who were followed up over a mean period of 76 months, the range being from 14 to 24 months.

\section{Methods}

PAR T I

By using short-term morbidity (anastomotic leak) and long-term recurrence as indices, an assessment has been made of the efficacy of some aspects of the surgical and medical management. These are the effect of a 'safety valve' ileostomy; the effect of unavoidably leaving diseased bowel at the level of the anastomosis; the prognostic significance of an anastomotic leak; and the effect of steroid therapy.

Received for publication 3 November 1970.
PART 2

Again, using the above indices, an assessment has been made of the criteria originally used in the selection of each patient for ileorectal anastomosis, namely, the age of the patient; the duration of the disease; the extent of the disease; the presence of perianal disease; and the sigmoidoscopic findings.

\section{PART 3}

Lastly a report has been made of the mortality among the patients; the fate of the patients who required a second operation; and the progress of the patients in this series in whom the operation was 'successful'.

\section{Results}

PART 1

There was a proven leak from the anastomotic site in eight patients $(32 \%)$, one of whom also developed intestinal obstruction. The leaks occurred between three and five days after operation and were treated by ileostomy and drainage in two, drainage alone in two, and by non-operative management in four patients. The response to treatment was satisfactory in all except one patient who had also developed intestinal obstruction and subsequently died.

The effect of a safety valve ileostomy (Table I)

Four patients received a defunctioning proximal loop ileostomy (Turnbull, Schofield, and Hawk, 1968) at the time of operation. Two leaked none- 


\begin{tabular}{llcll}
\hline $\begin{array}{l}\text { No. of } \\
\text { Patients }\end{array}$ & $\begin{array}{l}\text { Anastomotic No Leak } \\
\text { Leak }\end{array}$ & $\begin{array}{l}\text { Subsequent } \\
\text { Closure }\end{array}$ & $\begin{array}{l}\text { Ileostomy } \\
\text { Retained }\end{array}$ \\
\hline 4 & 2 & 2 & 3 & 1 \\
\hline
\end{tabular}

Table I The effect of a 'safety valve' ileostomy

theless (and are included in the four treated by nonoperative management). Closure was later effected in three of these patients but one patient prefers to retain the ileostomy.

The effect of unavoidably leaving diseased bowel at the level of the anastomosis

(1) Short-term morbidity (Table II): the ileal cuff was reported macroscopically normal in all cases although in 12 patients some ileal resection was required to make it so and in two other patients a skip lesion was left behind in the proximal ileum. Diseased rectum, however, was left behind in nine patients and of these three leaked $(33 \%)$. By comparison the rectum was free of disease in 16 patients and five leaked $(31 \%)$.

\begin{tabular}{lllll}
\hline $\begin{array}{l}\text { No. of } \\
\text { Patients }\end{array}$ & $\begin{array}{l}\text { Anastomotic } \\
\text { Leak }\end{array}$ & $\begin{array}{l}\text { Recurrence } \\
\text { of Disease }\end{array}$ & No Leak & $\begin{array}{l}\text { Recurrence } \\
\text { of Disease }\end{array}$ \\
\hline $\begin{array}{l}\text { Through diseased rectum } \\
9\end{array}$ & & & \\
\hline $\begin{array}{l}3(33 \%) \\
\text { Through normal rectum } \\
16\end{array}$ & None & 6 & $6(100 \%)$ \\
Total & $5(31 \%)$ & $3(38 \%)$ & 11 & $6(35 \%)$ \\
\hline
\end{tabular}

Table II The effect of unavoidably leaving diseased bowel at the level of the anastomosis

(2) Disease recurrence: both patients in whom ileal skip lesions were left behind have developed ileal recurrence. Of the nine patients where rectal disease was left behind, two are well with no evidence of recurrence, one died soon after operation, and six have developed recurrence.

It seems that the clearance of all macroscopic rectal disease has an important bearing upon the chance of long-term success of an ileorectal anastomosis. There are eight successful patients in the group of 16 whose anastomoses were clear of disease $(50 \%)$ whereas only two successful patients come from the group of nine where the anastomosis was made through diseased rectum ( $22 \%)$.

The prognostic significance of an anastomotic leak Of the eight patients in whom there were leaks four remain well with no evidence of recurrence $(50 \%)$. One patient died soon after operation and three patients have now developed recurrence $(38 \%)$. Of the 17 patients in whom there was no leak, only five remain well with no evidence of recurrence $(29 \%)$.

The effect of steroid therapy (Table III)

In this series 18 patients were prescribed steroids (or ACTH) for a period of time during their disease. In six of these there were leaks $(33 \%)$ and 11 developed a recurrence of the disease $(61 \%)$. By comparison, of the seven who were never on steroids the anastomosis leaked in two $(29 \%)$ and four developed disease recurrence $(51 \%)$. The average period of preoperative therapy was 12 months (range one month to seven years) and in all patients except one the reason for starting steroids was an exacerbation of the proctitis, the exception being because of systemic manifestations of the disease. Recurrence occurred in five of the 11 patients in the face of steroid therapy at intervals ranging from five to 22 months (mean 11 months). In the remaining six patients steroids were discontinued after operation and recurrence occurred at intervals ranging from three to 46 months (mean 20 months).

\begin{tabular}{lll}
\hline $\begin{array}{l}\text { No. of } \\
\text { Patients }\end{array}$ & $\begin{array}{l}\text { Anastomotic } \\
\text { Leak }\end{array}$ & $\begin{array}{l}\text { Recurrence } \\
\text { of Disease }\end{array}$ \\
\hline $\begin{array}{l}\text { On steroids } \\
18\end{array}$ & $6(33 \%)$ & $11(61 \%)$ \\
& \\
$\begin{array}{l}\text { Never on steroids } \\
7\end{array} \quad 2(29 \%)$ & $4(51 \%)$ \\
\hline
\end{tabular}

Table III The effect of steroid therapy

PART 2

An assessment of the criteria originally used for selecting the patients for ileorectal anastomosis in relation to the likelihood of recurrence.

The age of the patient (Fig. 1)

In this series the average age of the patient at operation was 30 (range 11 to 59). There was no difference between the recurrence rate for those younger than 30 than for the older patients.

\section{The duration of disease (Fig. 2)}

The average duration of illness before operation in all patients was four years (range two months to 27 years). There was no significant difference in the recurrence rate between those who had had a history shorter than four years and those whose duration of disease was longer.

The extent of the disease (Table IV)

The findings at the original operation showed that 14 patients had small as well as large bowel disease. Of these recurrence occurred in 10 patients $(71 \%)$. 

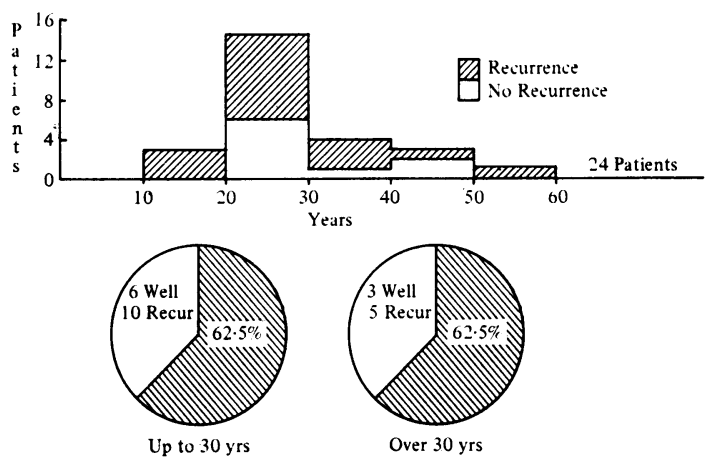

Fig. 1 Association of age at operation with recurrence.

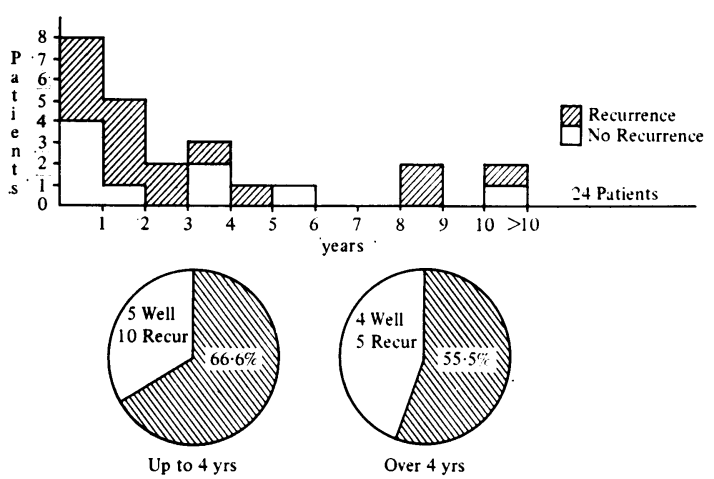

Fig. 2 Association of duration of disease before operation with recurrence.

In four patients the recurrence was in the ileum alone, in three in the rectum alone, and in three in both ileum and rectum.

By comparison, of those 11 patients in whom the large bowel alone was involved recurrence developed in five $(45 \%)$. The recurrence was in ileum alone in one, in rectum in two, and in both in two.

\section{Perianal disease}

Fissures, fistulae in ano, and recurrent ischiorectal

\begin{tabular}{lllll}
\hline $\begin{array}{l}\text { No. of } \\
\text { Patients }\end{array}$ & Recurrence & Distribution & \\
\cline { 3 - 4 } & & Ileum & Rectum & $\begin{array}{l}\text { Ileum and } \\
\text { Rectum }\end{array}$
\end{tabular}

Small and large bowel disease found at operation

$14 \quad 10(71 \%) \quad 4 \quad 3$

Large bowel disease only

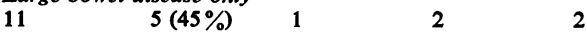

Table IV Association of recurrence with the original extent of the disease abscesses were reported in six patients in the years before operation. In none of these patients were the lesions active at the time of operation. Subsequently, fissures and fistulae were reported in four of the six and in one of these the lesions were sufficiently severe to lead to proctectomy 22 months after operation.In three of the six patients at two, five, and six years after operation there is moderate anal stricture. In one other patient, fistulae in ano developed spontaneously two years after operation.

\section{The sigmoidoscopic findings}

Sigmoidoscopy was performed before operation in all patients. Gross disease was found in none and this is presumably the reason why they were selected for ileorectal anastomosis. Where rectal biopsies were taken all showed non-specific chronic inflammatory reaction except in one, where sarcoid foci were also found. Sigmoidoscopic findings were no different in the eight patients whose anastomoses leaked than in those who did not leak, although one of the patients who leaked had had severe proctitis one year before.

PART 3

\section{Mortality}

Three patients died. The first died following intestinal obstruction and anastomotic leak seven days after ileorectal anastomosis. The illness was complicated by the presence of amyloid disease and the duration of the disease was six years.

The second patient died a month after further resection of the ileorectal anastomosis from renal failure associated with hypertension induced by steroid therapy. The duration of the disease was 11 years and the interval between operations 32 months.

The third died 13 months after ileorectal anastomosis from an exacerbation of recurrent disease associated with electrolytic imbalance. The duration of the illness was four years.

The fate of patients who required a second operation Ten patients underwent further surgery. Four had resection followed by a new ileorectal anastomosis; four had proctectomy and ileostomy; one had an ileostomy with Hartman's closure of the rectal stump; and one ileostomy with mucuous fistula. Of the four with resection, two are well 77 and 112 months after the second operation, one developed a further recurrence at the anastomosis 56 months after the second operation, and the fourth patient died (the second case in the mortality series). Of the four patients who have had proctectomy and ileostomy all are well 24, 41, 82, and 101 months 
following this operation and none have had stomal or ileal recurrence. One patient is well 17 months after the ileostomy with Hartman's procedure but the patient with ileostomy and mucuous fistula shows evidence of continuing rectal disease.

\section{The progress of the successful patients}

There are 10 patients ( $40 \%$ of the series) who can be classified as having a successfully functioning ileorectal anastomosis, although two of these have required re-resection because of recurrent disease. One further patient who had a proximal loop ileostomy because of a leak has elected to retain the ileostomy despite the presence of a 'normal' ileorectal anastomosis.

Eight of the 10 patients were on steroids and all are now off the drug. One patient (previously reported) developed fistulae in ano in the second year after operation which responded to surgical treatment.

On sigmoidoscopy four patients only show some proctitis with rectal biopsies showing mild chronic inflammatory reaction. They are nonetheless free of symptoms. All report complete faecal continence and the frequency of bowel action is three or four times a day.

\section{Interpretation of Results}

\section{PART 1}

\section{Anastomotic leakage}

The evidence from this series shows that anastomotic leak may occur despite the presence of a 'safety valve' ileostomy. It also shows that a leak may occur with equal frequency $(38-36 \%$ ) whether or not the anastomosis is made through macroscopically diseased rectum and that a leak has no prognostic significance with regard to disease recurrence. It also shows that a higher proportion of successful patients come from the group where the anastomosis was made through macroscopically normal rectum $(50 \%)$ than when it was made through residual diseased rectum $(22 \%)$.

\section{Steroid therapy}

In this series steroid therapy did not appear to predispose to the development of an anastomotic leak. Seventy-five per cent of those in whom there were leaks and $71 \%$ of those in whom there were none were on steroids. Nor did steroids appear to have any effect upon the development of disease recurrence. Sixty-one per cent of those who were or had been on steroids developed recurrence, whereas $57 \%$ of those who had never been on steroids also developed recurrence.
PART 2

In this series neither the age of the patient nor the duration of the disease had any bearing on disease recurrence. Seventy-one per cent of those patients who had concurrent small bowel disease developed recurrence compared with $45 \%$ of those with large bowel disease alone. As might be anticipated, recurrence occurred more frequently in the small bowel in the first group although the numbers are too few to give significance to this difference. Patients with gross perianal disease were presumably not selected for ileorectal anastomosis and this would explain the small number of lesions reported in this series. Subsequent perianal lesions led to proctectomy in only one patient.

Sigmoidoscopic findings before operation gave no indication as to the likelihood of leak or future recurrence although the relatively normal appearances must have influenced the decision to perform ileorectal anastomosis.

Eight patients (32\%) qualify as 'successes' in that they have developed no anastomotic recurrence of their original disease. Two other patients having had a revision ileorectal anastomosis for recurrence are well, making a total of 10 patients ( $40 \%$ ) classified as successes. One patient prefers to retain the ileostomy and five have required an ileostomy and are now well. It could be argued that ileostomy was at least deferred for from 17 to 101 months in the latter five patients and that this in itself is a reasonably satisfactory result. The mortality rate in this series, however, was $12 \%$ and the overall disease recurrence rate was $60 \%$.

It seems that disease recurrence is the most important factor that should be considered before advising ileorectal anastomosis. Jones et al (1966) reported a recurrence rate of $47 \%$ (16 patients out of 38 who had undergone subtotal colectomy and anastomosis) and Turnbull et al (1968) reported recurrence in $32 \%$ (22 patients out of 68 followed up who had undergone ileorectal anastomosis). From the point of view of avoiding recurrence the alternative of proctocolectomy is not as attractive as it might seem to be at first sight. Hawk and Turnbull (1966) report postcolectomy ileitis in $20 \%$ of their Crohn's colitis patients treated by proctocolectomy (17 patients out of 87) and we have found this in 16 out of $31(52 \%)$ (Cooke, Burman, and Williams, 1970).

If, between the two operations, the risk of recurrence is not dissimilar and in the absence of any factor which can specifically help in the selection of the operation it is felt that ileorectal anastomosis remains a suitable procedure for Crohn's disease of the large bowel. 
References

Cooke, W. T., Burman, J. H., and Williams, J. A. (1970). Post colectomy ileitis. Unpublished data.

Hawk, W. A., and Turnbull, R. B., Jr. (1966). Primary ulcerative disease of the colon. Gastroenterology, 51, 802-805.

Hawk, W. A., Turnbull, R. B., Jr., and Schofield, P. F. (1970). The natural history of postcolectomy ileitis. Proc. roy. Soc. Med. 63, 68-73.
Lindner, A. E., Marshak, R. H., Wolf, B. S., and Janowitz, H. D. (1963). Granulomatous colitis: a clinical study. New Engl. J. Med., 269, 379-385.

Jones, J. H., Lennard-Jones, J. E., and Lockhart-Mummery, H. E. (1966). Experience in the treatment of Crohn's disease of the large intestine. Gut, 7, 448-452.

Turnbull, R. B., Jr., Schofield, P. F., and Hawk, W. A. (1968). Nonspecific ulcerative colitis. Advanc. Surg. (Chic.), 3, 161-225. 